\title{
Inclusive ICTs in Education
}

\author{
Mohamed Koutheair Khribi \\ Mada Center
}

There is no doubt that education is one of the most vital areas in societies, as the development and progress of peoples are mainly linked to the effectiveness and quality of their education systems. Today in the digital age, learners are looking for innovative learning opportunities beyond the one size fits all and traditional classroom-based approaches harnessing the power of information and communication technologies ICTs. Indeed, availing digital technologies became a necessity for education systems as they offer unprecedented opportunities for all learners, with different abilities, needs, and disabilities, to learn effectively and overcome (or at least reduce) barriers prohibiting them to access education and enjoy meaningful learning experiences. This paper introduces main concepts related to inclusive ICTs in education and explores ways to make them accessible for all.

It is the right of all students, especially those with different abilities, needs, and disabilities, to have equal learning opportunities. Inclusive education, as stated in the broad definition set out by UNESCO (2009), entails enhancing the ability of the educational system to reach all learners, in a way that will support equity for the benefit of all learners without exception, especially those with disabilities.

The United Nations Convention on the Rights of Persons with Disabilities UNCRPD urges all countries to take a number of important measures to overcome the obstacles that prevent learners with disabilities from accessing education and availing inclusive ICTs that facilitate inclusive education (Article 9 on accessibility, and Article 21 on freedom of expression, opinion and access to information, and Article 24 on education). This actually requires tremendous work to provide equitable learning opportunities, support education services, and create an enabling environment that will help learners, especially those with disabilities, accessing quality education and benefiting from the potential of ICTs.

Equally important, the Sustainable Developement Goals SDGs of the 2030 UN Agenda, designed to achieve a better and more sustainable future for all, draw on the principles of access, and equity, and inclusiveness towards building sustainable knowledge-based societies. The fourth goal (SDG 4) focuses on achieving quality education for all: "Ensuring inclusive and equitable quality education for all and promoting lifelong learning opportunities for all". On that premise, ICTs play a primary role toward ensuring 


\section{Nafath}

Issue 17 - May 2021

access to quality education for all, provided that all learners, especially those with disabilities, can access and avail these technologies, and improve accordingly their learning experiences. Hence, there is a profound need to promote the effective use of inclusive ICTs in education for learners with disabilities. Nevertheless, such technologies would be profitable for learners with disabilities if and only if barriers (i.e. physical, financial, cognitive, didactical, and content) hindering access to them are removed or at least reduced. To this end, it is required that appropriate ICTs facilitating inclusive education, are universally accessible and compatible with assistive technology in order to support as much as possible diversity, in particular for learners with disabilities, improving thus their educational attainment.

According to the "Model Policy for Inclusive ICTs in Education for Persons with Disabilities" report, which is part of the United Nations Educational, Scientific and Cultural Organization (UNESCO) and Global Initiative for Inclusive Information and Communication Technologies (G3ict) joint efforts to facilitate the implementation of the UNCRPD, Inclusive ICTs for education include:

Mainstream technologies readily available in the marketplace, e.g. computers, web browsers, software, text editors, word processors, whiteboards, mobile devices, etc. for all learners ;

Assistive Technologies mitigating difficulties in using mainstream technologies, e.g. screen readers, alternative mice and keyboards, augmentative and alternative communication devices, and other specific applications ;

Compatibility between assistive technology products and mainstream technologies;

Accessible media and formats e.g. word and presentation documents, Web files, multimedia, DAISY (Digital Accessible Information System) books, EPUB, PDF files, etc ;

Accessible digital educational resources;

Accessibile e-learning platforms and tools e.g. Learning Content Management Systems LMS, Virtual Classrooms, Authoring tools, Courseware, and repositories, etc.

Furthermore, coupled with providing inclusive ICTs for learners with disabilities, promoting open and digital education can help a lot in reducing barriers and enabling all learners, especially those with disabilities to access the same educational opportunities, according to their needs, time, pace, device, and location.

Above all, for digital education to be inclusive and accessible for all learners, digital tools, platforms, contents, and education technologies must, in turn, be accessible, and properly and universally designed to scaffold and enable each and every learner to learn effectively considering her/his abilities, disabilities, and individual learning preferences. 


\section{Nafath}

Issue 17 - May 2021

For this reason, e-learning platforms, educational contents and applications should enable learners to use accessibility features and ensure compatibility with assistive technologies, so that it can be accessed and presented properly and in multiple ways fitting the needs and preferences of learners (e.g. enlarging and selecting fonts, adjusting color contrast and display preferences, using alternative texts for images and visuals, adapting page content, simplifying interfaces, using screen readers, keyboard navigation, etc.).

All things considered; it is important to consider that achieving inclusive education harnessing the power of ICTs requires mainly:

- Establishing supportive policies and strategies.

- Raising awareness, capacity development, and continuous training.

- Reducing barriers to accessing appropriate ICTs.

- Providing appropriate accessibility solutions and assistive technology.

- Ensuring the accessibility of e-learning platforms and digital education content.

- Designing for everyone without exception and meeting the needs of different students, especially those with disabilities.

- Applying universal design for learning UDL guidelines and providing required editing and assessment tools.

With this in mind, we must not lose sight of the fact that education in the era of digital transformations should not focus and depend solely on using technologies and related trends. Rather, inclusive technologies should be effectively harnessed in a bid to enabling all learners to reach their learning goals and supporting their individual learning styles and special needs in order to let them be well prepared for inclusion and adapted to future changes, towards building inclusive sustainable knowledge-based societies. 